\title{
Analysis of Accidents in 6-110 KV Electric Networks of Kuzbass Power System
}

\author{
Sergei Zakharov ${ }^{1 *}$, Dmitriy Kudryashov ${ }^{1}$, Viktor Brodt ${ }^{1}$, Ivan Pascar $^{1}$, and Vyacheslav \\ Voronin $^{1}$ \\ ${ }^{1}$ T.F. Gorbachev Kuzbass State Technical University, 650000, 28 Vesennyaya street, Kemerovo, \\ Russia
}

\begin{abstract}
Power system of the Kemerovo region is unique in terms of the number of hazardous production facilities (coal mines, coal pit). To ensure trouble-free operation of hazardous production facilities and the normal operation of other consumers, it is necessary to ensure reliable operation of regional electrical grid networks. Based on reports on technological disruptions in electric networks of the Kemerovo region in 2015, performed analysis of accidents in 6-110 kV electric networks of Kuzbass power system. The statistics of the technological disruptions in terms of voltage classes, damaged elements, causes of occurrence, time to recovery and the number of outages of household consumer, are given. Conclusions were drawn about the high level of accident rate in $6-10 \mathrm{kV}$ electrical network.
\end{abstract}

\section{Introduction}

The Kemerovo region is a large industrial region and plays an important role in the economy not only of Siberia, but of the whole Russia. The basic industries of the region are the coal industry and metallurgy, as well as the chemical industry, power engineering and machine-building branch. In the Kemerovo region located a lot of large industrial enterprises, some of which are hazardous production facilities. For trouble-free operation of such consumers it is important to ensure reliable operation of their external power supply system and the power system of the Kemerovo region as a whole.

\section{Materials and Methods}

The object of study in this paper are the 6-110 kV electric network of the power system of the Kemerovo region. Based on reports on technological disruptions in electric networks of the Kemerovo region in 2015, performed analysis of accidents in electric networks of Kuzbass power system.

\footnotetext{
"Corresponding author: zsa.egpp@kuzstu.ru
} 


\section{Results and Discussion}

The study analyzed more than 5000 technological disruptions (TD) that occurred in 6-110 $\mathrm{kV}$ electric grids of the power system of the Kemerovo Region. The distribution of TD by seasons is as follows: winter $-20.78 \%$ : spring $-26.35 \%$; summer $-35.43 \%$; autumn $17.43 \%$. About half of all TD occurred in the period from May to August.

More than half of the TD (51.47\%) occurred in $10 \mathrm{kV}$ electric networks, and about one third of TD (32.82\%) occurred in $6 \mathrm{kV}$ electric networks (Fig. 1).

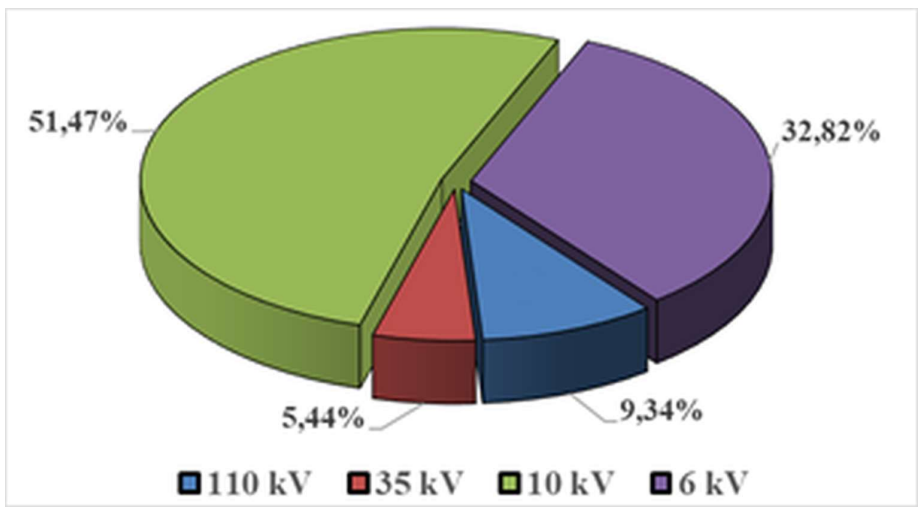

Fig. 1. Distribution of technological disruptions by voltage classes.

The average duration of a power supply disruption to consumers as a result of the TD was 1 hour 54 minutes. About $35 \%$ of all TD did not lead to power outages due to redundancy and grid automation system.

About $40 \%$ of all TD caused a violation of electricity supply to residential consumers. On average, after each power outages without electricity remained approximately 814 people. The most serious accident resulted in power outages of 84 thousand people.

The distribution of TD for power system objects is shown in Fig. 2. The reason for the majority of TD $(66 \%)$ is unknown to authors. Among the remaining TD, the largest share falls on overhead power transmission lines (OTL) $(16.5 \%)$ and cable transmission lines (CTL) $(8.38 \%$ ), also a lot of TD occurred due to damage to substation equipment $(6.72 \%)$.

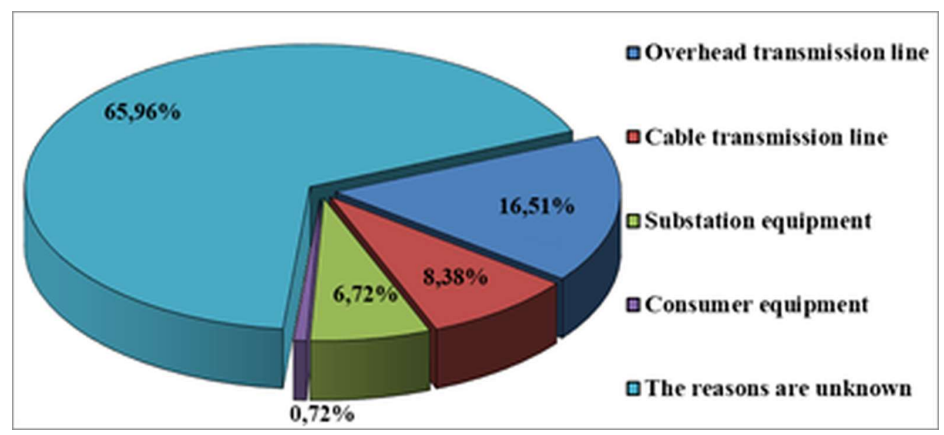

Fig. 2. The diagram of the distribution of technological disruptions on the objects of the power system of the Kemerovo region.

Many of the TD occurred due to the impact of weather conditions (thunderstorm, gusty winds, etc.). About $18 \%$ of all TD occurred during inclement weather (most often in the spring and summer season). Overhead transmission lines are most affected by weather effects $(18.42 \%$ of TD occurred during inclement weather). In addition, $21.82 \%$ of all TD with unknown cause has occurred during inclement weather. 
Damage to the OTL on average leads to a power outage of about 1,089 people for 2 hours 23 minutes. The most common cause of TD that occurred in the OTL (Fig.3a) is wire breakage $-31.53 \%$, damage to insulator $-19.56 \%$ (including insulator flashover), ingress of foreign objects $-14.36 \%$ (falling trees, branches, contact with animals and other objects). The ctegory of natural phenomena $(1.14 \%)$ includes the formation of a large amount of ice on the wires, the passage of landslides, the direct hit of a lightning. Over $80 \%$ of all TD in OTL occurred in 6-10 kV networks.

Damage to the CTL on average leads to a power outage of about 750 people for 2 hours 12 minutes. Information about the causes of more than half $(55.53 \%)$ of the TD in CTL is absent. Among the known causes of TD (Fig.3b), the largest number is due to breakdown of cable insulation (31.15\%). Significantly fewer TD occurred as a result of third party action $(5.74 \%)$ and damage to the cable gland (5.33\%).

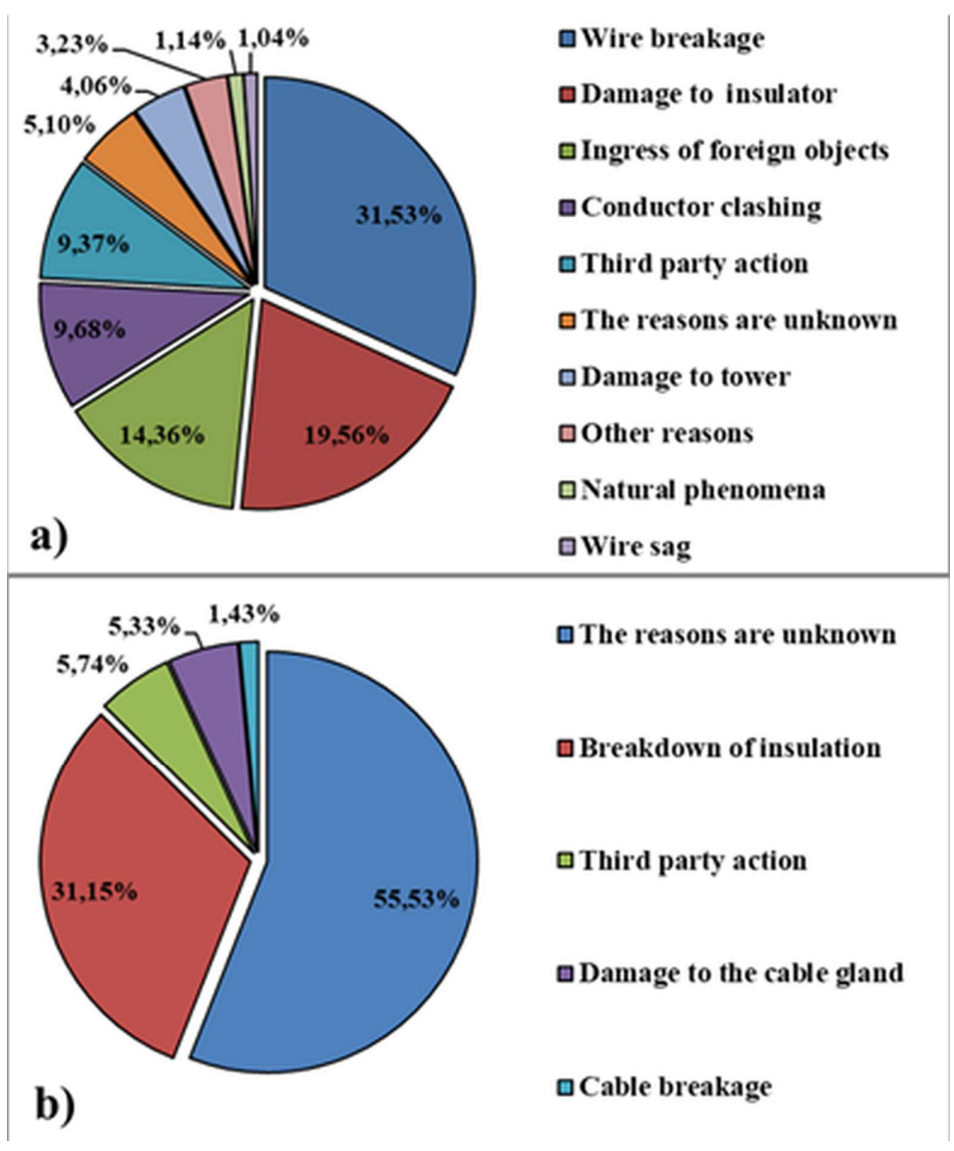

Fig. 3. The diagram of the distribution of the causes of technological disruptions on: a - overhead transmission line;

$\mathrm{b}$ - cable transmission line

Accidents on the substations on average leads to a power outage of about 921 people for 2 hours 14 minutes. Accidents on the substations on average leads to a power outage of about 921 people at 2 hours 14 minutes. Most often, TD are associated with failures of switch device $(37.15 \%)$, accidents on the transformer substation $(23.66 \%)$ and failures of power transformer (13.23\%) (Fig. 4). Among the switching devices greatest number of failures occurred with disconnecting devices. 


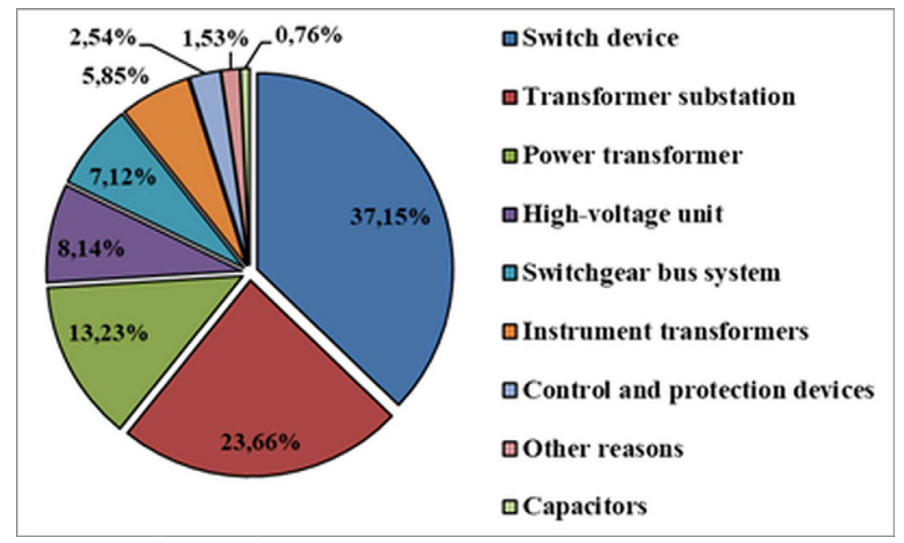

Fig. 4. The diagram of the distribution of the causes of technological disruptions on substation equipment

The obtained results correspond to the previously published surveys of accidents in the electric networks of Kuzbass [1,2].

The greatest number of accidents in the power system of the Kemerovo region has occurred in 6-10 kV electrical networks. The consequences of accidents in networks of higher voltage classes are heavier (TD in the $110 \mathrm{kV}$ network on average leads to a power outage of about 3,047 people, in $35 \mathrm{kV}$ network - 2,486 people), however, their total number is only about $15 \%$ of the total number of TD. Single outage in $6-10 \mathrm{kV}$ networks result in less serious consequences, however, due to their large number, the total number of consumers without electricity, as a result of TD in 2015 in $6-10 \mathrm{kV}$ networks, is almost 3 times higher than for $35-110 \mathrm{kV}$ networks.

Improving the reliability of OTL will significantly increase the reliability of the power system of the Kemerovo region as a whole. According the results of analysis, as well as the study of many authors [1-5], the main cause of damage to OTL is equipment wear and climatic effects. The influence of weather on the reliability of OTL discussed in numerous papers, for example [6-13].

To improve the reliability and reduce the impact of weather conditions on OTL of voltage class $110 \mathrm{kV}$ and above in study [7, 8, 15] recommended implementing the following measures: use of wires of new generation; reduction in the length of spans; use of polyhedral supports.

For 6-10 kV OTL in study $[13,14]$ recommended to use insulated wires, timely clearing of power line glades and to use automatic partitioning of the network.

\section{Conclusions}

The greatest number of accidents in the power system of the Kemerovo region has occurred in $6-10 \mathrm{kV}$ OTL $(11.7 \%$ of the total number of TD and $35.7 \%$ of the number of TD with known causes).

To reduce the accident rate in the electric grids of the Kuzbass power system, it is recommended to implement the following measures in 6-10 $\mathrm{kV}$ networks: replacement of bare conductors to the insulated; timely clearing of power line glades; introduction of automatic partitioning. 


\section{References}

1. S. G. Zakharenko, T. F. Malakhova, S. A. Zakharov, Kuzbass State Technical University Bulletin, 4, 95 (2016)

2. I. V. Sarychev, Kuzbass State Technical University Bulletin, 3, 15 (2005)

3. G .F. Kutsenko, O.Yu. Pukhal'skaya, Energetika SNG, 6, 2 (2006)

4. A.V. Vinogradov, R.A. Per'kov, Bulletin NGII, 12, 12 (2015)

5. M. I. Toshkhodzhaeva, Cherepovets State University Bulletin, 1, 105 (2016)

6. A. N. Shilin, O. I. Doronina, Izvestia VSTU, 6, 76 (2014)

7. N. Yu. Shevchenko, Yu. V. Lebedeva, G. G. Ugarov, Bulletion SSTU, 1, 119 (2011)

8. N. Yu. Shevchenko, Yu. V. Lebedeva, A. G. Soshinov, Izvestia VSTU, 2, 77 (2009)

9. N. M. Shauleva, A. G. Zakharova, D. K. Starichenko, Kuzbass State Technical University Bulletin, 1, 114 (2010)

10. D. M. Ward, Climatic Change, 121, 103 (2013)

11. E. P. Nikiforov, Power Technology and Engineering, 38, 49 (2004)

12. Yu. S. Zhelezko, V. A. Kostyushko, S. V. Krylov, E. P. Nikiforov, O. V. Savchenko, L. V. Timashova, E. A. Solomonik, Power Technology and Engineering, 39, 51 (2005)

13. A. M. Korotkevich, V. F. Kudryashov, M. A. Drako, Energiya i menedzhment, 4(5), 37 (2013)

14. L. I. Doletskaya, V. P. Kavchenko, R. V. Solopov, Naukovedenie, 6, 1 (2015)

15. L. V. Timashova, E. P. Nikiforov, I. A. Nazarova, Energy of Unified Grid, 5, 6 (2014) 